\title{
Effect of ectoparasite infestation density and life-history stages on the swimming performance of Atlantic salmon Salmo salar
}

\author{
S. Bui ${ }^{1, *}$, T. Dempster ${ }^{1,2}$, M. Remen ${ }^{2}$, F. Oppedal ${ }^{2}$ \\ ${ }^{1}$ Sustainable Aquaculture Laboratory - Temperate and Tropical (SALTT), School of BioSciences, University of Melbourne, \\ Victoria 3010, Australia \\ ${ }^{2}$ Institute of Marine Research, Matredal 5984, Norway
}

\begin{abstract}
To overcome sustainability obstacles and improve operations, the Atlantic salmon farming industry is testing novel approaches to production. Redistributing farm sites to offshore locations is one such solution; however, tolerance to high-current velocity sites must be considered, particularly if fish health status is compromised by parasites. We tested the effect of parasite density and life-history stage on the swimming performance of Atlantic salmon Salmo salar using a swim flume. Salmon with 3 different salmon lice Lepeophtheirus salmonis densities $(0,0.02 \pm$ 0.01 and $0.11 \pm 0.01$ lice $\mathrm{cm}^{-2}$ [mean $\pm \mathrm{SE}$ ]) were tested across the 4 major life-history stages of lice (copepodid, chalimus, pre-adult and adult) for critical swimming performance $\left(U_{\text {crit }}\right)$. Salmon $U_{\text {crit }}$ declined slightly by a mean of 0.04 to 0.10 body lengths $\mathrm{s}^{-1}$ with high parasite densities compared to uninfested and low densities, across the lice stages, while progression through the parasite lifehistory stages had little effect on swimming performance. Our results suggest that increasing infestation density of salmon lice incurs negative fitness consequences for farmed Atlantic salmon held in high-current velocity sites, with little difference in costs associated with attachment by different life-history stages of the lice.
\end{abstract}

KEY WORDS: Salmonid $\cdot$ Salmon louse $\cdot$ Critical swimming speed $\cdot$ Swim flume $\cdot$ Copepod Exposed aquaculture

\section{INTRODUCTION}

Numerous performance measures combine to determine individual fitness, and for aquatic animals, swimming is a key component of fitness in a challenging environment (Videler 1993). Swimming performance plays a vital role in predator avoidance, feeding behaviours, social interactions and migrations, and impairment of maximal swimming capacity may reduce an individual's ability to evade attack, hunt prey, keep up with a school or avoid suboptimal environmental conditions (Plaut 2001). Swimming performance can be reduced by parasites that force hosts to divert some of their energetic budget towards dealing with infestation, via immune or physi-

*Corresponding author: samanthab@unimelb.edu.au ological responses, and away from locomotion or metabolic activities (Barber et al. 2000).

The ectoparasitic sea louse Lepeophtheirus salmonis infests salmonids across the northern hemisphere, and represents a substantial problem in the aquaculture of Atlantic salmon Salmo salar (Torrissen et al. 2013, Murray et al. 2016). The parasite negatively affects the welfare status of farmed salmon, causes production and economic losses, and depresses wild salmonid populations in nearby environments due to parasite spill-back (Costello 2006, 2009, Krkošek et al. 2007, Thorstad et al. 2015). Sea lice have planktonic and attached stages that utilise a single salmonid host (Costello 2006). The freeswimming copepodid stage exhibits host-searching

() The authors 2016. Open Access under Creative Commons by Attribution Licence. Use, distribution and reproduction are unrestricted. Authors and original publication must be credited. 
behaviours, and when a salmonid is encountered, they attach and progress through their life-history stages on the host (Johnson \& Albright 1991). Infestation is associated with negative physiological and immune responses, with the different life-history stages inflicting varying levels of reaction (Grimnes \& Jakobsen 1996, Wagner et al. 2008). Current knowledge predicts that most physiological harm occurs to the host immediately after the lice moult from the attached chalimus stage to the mobile preadult stage, largely due to the change in feeding behaviour (Jónsdóttir et al. 1992). Infestations are energetically costly, with infestations by adult lice reducing the critical swimming speed for Atlantic salmon (Wagner et al. 2003, Wagner et al. 2008).

Any impairment of fitness caused by sea lice infestation is expected to vary with the degree of their interaction with the host, through feeding characteristics, infestation density, or life-history stage (Wagner et al. 2008). The domesticated habitat of farmed salmon results in an altered host-parasite interaction; e.g. in Norway, regulations stipulate a threshold for parasite intensity, requiring that fish must be treated when parasite levels reach an average of 0.5 adult female sea lice per fish (Torrissen et al. 2013). Farmed salmon individuals therefore rarely carry high loads of adults, but will often harbor higher densities of earlier life-history stages. In contrast, wild salmonids can carry all life-history stages in high densities (Thorstad et al. 2015). The impact of parasite burden on individual fitness and survival from reduced swimming capabilities is likely to differ substantially between farmed and wild salmon. Farmed salmon are restricted to their caged microenvironment, where fluctuating current velocities require fish to alter swimming performance to maintain position in the school and avoid the net wall (Johansson et al. 2014). Wild salmon post-smolts must maintain their swimming performance to reach feeding areas in the ocean, and to migrate successfully up their natal stream and survive until spawning. In both cases, ectoparasitic infestation will decrease performance capacity (Wagner et al. 2003). However, we have little knowledge on the magnitude with which various sea lice stages diminish performance.

Measurement of critical swimming speed $\left(U_{\text {crit }}\right)$ is a common method of assessing the swimming performance of fish (Brett 1964, Hammer 1995), particularly when testing the effects of a biotic or abiotic factor on physiological performance (Kolok 1999). $U_{\text {crit }}$ is measured by placing a fish in a flume or flow tunnel, forcing them to swim against incrementally increasing current velocities, and using the time and velocity at exhaustion to calculate critical swimming speed for that individual (Brett 1964). Although the ecological relevance of $U_{\text {crit }}$ is debated, the general consensus is that it yields comparable data on the swimming ability of fish and accurately reflects physical status, from which fitness and survival can be inferred (Plaut 2001).

Here, we investigated the relationship between parasite load and swimming performance (as measured by $U_{\text {crit }}$ in post-smolt Atlantic salmon across the major life-history stages of salmon lice (copepodid, chalimus, pre-adult and adult stages). As the size of parasites increases and feeding characteristics intensify as life-history stages progress, particularly with the greater consumption rate and mobility of later stages, we predicted that their effect on swimming performance should scale similarly.

\section{MATERIALS AND METHODS}

Post-smolt Atlantic salmon Salmo salar were produced and held at the Norwegian Institute of Marine Research facilities. Experimental fish $(\mathrm{n}=330$, mean \pm SE: $80 \pm 1 \mathrm{~g}$ weight, $19.6 \pm 0.1 \mathrm{~cm}$ fork length) were netted from their holding tank and transferred to an anaesthetic bath (Finquel MS-222, tricaine methane-

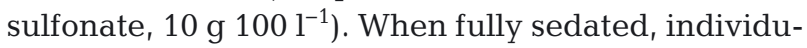
als were implanted with passive integrated transponder (PIT; Glass tag unique, $3.85 \times 23 \mathrm{~mm}$, Trac-ID Systems AS) tags into their abdominal cavity, then transferred into one of 3 holding tanks $(\varnothing=3 \mathrm{~m}$, $5.3 \mathrm{~m}^{3}$ ) for recovery. A total of 110 fish were held in each tank at $15^{\circ} \mathrm{C}$ with a natural light regime, and allowed to recover for $7 \mathrm{~d}$ before infestation.

\section{Sea lice production and infestation}

Holding tanks were randomly assigned treatments of lice infestation pressures: 0, 30 or 90 Lepeophtheirus salmonis copepodids per fish. Egg strings were collected from gravid females held at $15^{\circ} \mathrm{C}$ and incubated at the same temperature. When hatched and $>75 \%$ of lice were at the copepodid stage $(\sim 6 \mathrm{~d})$, the quantity of salmon louse copepodids was estimated using a microscope and counting chamber. Lice were divided into 2 containers for infestation ratios of 30 copepodids fish ${ }^{-1}$ and 90 copepodids fish $^{-1}$ (low and high infestation pressures, respectively) to gain an expected parasite load of 10 and 30, based on a $30 \%$ infestation success (Bjørn \& Finstad 1998). During infestation, total water volume was 
reduced from 5.3 to $2.65 \mathrm{~m}^{3}$ and flow stopped in all 3 holding tanks to prevent initial rising of water level and increase of infestation pressure. Copepodids were introduced to the 2 infestation tanks. After $20 \mathrm{~min}$, flow was increased to a low rate $\left(20 \mathrm{l} \mathrm{min}^{-1}\right)$ and after $3 \mathrm{~h}$, was fully restored to $80 \mathrm{l} \mathrm{min}^{-1}$. Oxygen was monitored throughout the infestation period to ensure levels were $>80 \%$ saturation at all times.

\section{Swimming performance challenge}

Performance challenges were conducted using a recirculating swim flume, constructed using polypropylene pipes forming an oval shape with 2 longer parallel sides, one of which contained the test chamber. The chamber was $248 \mathrm{~cm}$ long with an internal diameter of $36 \mathrm{~cm}$, with grids at the front and back of the chamber, and openings on the top where exhausted fish could be taken out. The current velocity was generated by a motor-driven propeller (Flygt 4630, $11^{\circ}$ propeller blade, Xylem Water Solutions Norge AS) mounted within another section of the flume, and propeller speed (in rounds per minute, rpm) was controlled by a panel located a distance from the flume, to prevent disturbance during the test. Calibration was made between rpm and $\mathrm{cm} \mathrm{s}^{-1}$ in the flume, and challenge velocities were converted between $\mathrm{cm} \mathrm{s}^{-1}$ and body lengths (BL) s${ }^{-1}$ to be specific to the size range of fish we used. A resting tank, honeycomb filter and reduction cone filter were also within the flume to control and fluid movement through the chamber. New seawater was provided to the system in between the swim chamber and propeller, sourced from an adjacent tank, and water flowed out via an outlet located behind the swim chamber.

Swimming performance challenges involved a total of 30 fish in the chamber, 10 from each of the 3 infestation pressure groups. Swim flume runs occurred in line with the predicted growth rate of the sea lice based on water temperatures, to capture periods when lice had moulted into specific lifehistory stages. Four stages (and therefore 4 sets of runs) were tested: the copepodid stage $(1 \mathrm{~d}$ postinfestation; dpi), chalimus stages $(7 \mathrm{dpi})$, pre-adult stages (14 dpi) and adult stage ( $20 \mathrm{dpi})$. For each lice stage, 3 replicate performance challenges were conducted on consecutive days, except for the copepodid stage. The time frame before which sea lice moulted into the next stage was $\sim 3 \mathrm{~d}$, only allowing for 2 replicate challenges for the copepodid stage. Five runs contained $<30$ fish due to mortality or, in the adult sea lice group, lack of parasitised fish for the high-range infestation pressure group. Runs never included $<25$ individuals in the swim flume.

When transferring fish into the swim flume, the water level was reduced in the holding tanks and the fish were lightly sedated (Finquel MS-222, tri-

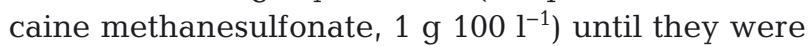
unresponsive to external stimuli. Random individuals were caught by hand and placed in a small con-

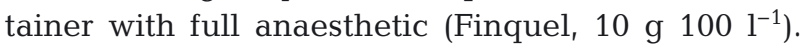
Upon loss of consciousness, parasite load was assessed, PIT-ID recorded, and the fish was put into the swim flume with no flow. MS-222 has little to no effect on crustaceans at doses applicable to fish (Schmit \& Mezquita 2010) and therefore was not expected to affect sea lice attachment. Recovery of sedated fish was monitored inside the flume, and when all fish had regained normal swimming activity, the swim flume was set to a velocity of $\sim 0.5 \mathrm{BL}$ $\mathrm{s}^{-1}$. Following standard protocols (see Plaut 2001 and references within), fish were left to acclimatize overnight, after which any effect of anaesthesia on swimming performance is negligible (Hayashida et al. 2013). Some mortalities occurred overnight due to fish escaping from the chamber.

The protocol for performance testing used increasing velocity increments of $0.5 \mathrm{BL} \mathrm{s}^{-1}$, following established methodology (Kolok 1999). Velocities inside the swim chamber were confirmed using a handheld velocimeter (Vane Wheel FA, with ZS25 insertion probe connected to handheld flowtherm NT, by Höntzsch) mounted in the centre of the chamber. We recorded velocities with increasing speed intervals, without fish and with a group of 25 fish (pilot). The relationship between propeller speed and predicted current velocity was accurate with and without fish $\left( \pm 1.5 \mathrm{~cm} \mathrm{~s}^{-1}\right)$, so the velocimeter was removed for performance challenges to prevent fish from using it as a hydrodynamic shelter.

After the acclimatisation period, the challenge began at $0.5 \mathrm{BL} \mathrm{s}^{-1}$, and increased by increments of $0.5 \mathrm{BL} \mathrm{s}^{-1}$ at 20 min intervals (Kolok 1999). During the challenge, a camera was mounted behind the back grill facing the swimming chamber, so that fish could be observed without disturbance. Exhausted fish were detected using the camera and were rapidly removed from the chamber by hand. Fish were considered exhausted when they no longer swam against the current and lay on the back grill with no attempt to escape when touched. The velocity at which exhaustion occurred and the time elapsed since the beginning of that speed increment was recorded for each individual. Fish were euthanised immediately 
when taken out of the flume using an overdose of anaesthesia. Individuals were continuously removed from the flume upon exhaustion and the velocity increased incrementally until all fish were fatigued. Following the trial, all fish were weighed, measured, and had their PIT-ID recorded.

Critical swimming speed was calculated by: $U_{\text {crit }}=$ $V+\left(t \Delta t^{-1}\right) \Delta V$, where $V=$ highest velocity maintained $\left(\mathrm{cm} \mathrm{s}^{-1}\right), t=$ time elapsed at final velocity (min), $\Delta t=$ time increment and $\Delta v=$ velocity increment (Brett 1964). As critical swimming speed values have a strong relationship with fish length, we converted $U_{\text {crit }}\left(\mathrm{cm} \mathrm{s}^{-1}\right)$ to relative $U_{\text {crit }}\left(\mathrm{BL} \mathrm{s}^{-1}\right)$ by dividing the absolute swimming speed by the individual's fork length $(\mathrm{cm})$.

\section{Statistical analysis}

As the settlement success of parasites increases with host size and the available surface area (Tucker et al. 2002), we standardised infestation intensity to fish body size. The total number of attached lice was converted to lice density using a model formula for fish surface area $(S)$, where area $\left(\mathrm{cm}^{2}\right)$ was calculated using $S=0.72 L^{1.88}(L=$ total length; O'Shea et al. 2006). The relationship among parameters was assessed using multiple regression (Field et al. 2012) in R version 3.1.0 (R Core Team 2015). To investigate which factors influenced $U_{\text {crit }}$ $\left(\mathrm{cm} \mathrm{s}^{-1}\right)$, we included lice stage (categorical factor converted to dummy variables for contrasts against the base category, copepodid stage), lice density, and fish length as predictor variables in the full model and tested using the linear model function. Diagnostic plots were assessed to check model assumptions. Models including only one predictor variable term were also run to examine the improvement of the full model with the inclusion of the variables in question. Pair-wise comparisons of the models using ANOVAs were conducted to determine the improvement of the full model with inclusions of predictor variables.

\section{RESULTS}

The infestation protocol was successful, with $100 \%$ prevalence of sea lice at the copepodid stage. For the copepodid, chalimus and pre-adult stages, average lice density per fish increased with the initial infestation intensities of 0,30 and 90 copepodids per fish (Table 1). However, pre-adult stages of sea lice did not survive well as abundance in the low and high infestation pressure tanks declined after sea lice had progressed to the adult stage (Table 1).

Mean $U_{\text {crit, }}$ averaged across the lice stages and fish lengths, was (mean $\pm \mathrm{SE}$ ) $80.59 \pm 0.52 \mathrm{~cm} \mathrm{~s}^{-1}(4.09 \pm$ $0.03 \mathrm{BL} \mathrm{s}^{-1}$ ) for unparasitised fish, $80.86 \pm 0.52 \mathrm{~cm} \mathrm{~s}^{-1}$ $\left(4.15 \pm 0.03 \mathrm{BL} \mathrm{s}^{-1}\right)$ for fish with low parasite load, and $78.55 \pm 0.46 \mathrm{~cm} \mathrm{~s}^{-1}\left(4.05 \pm 0.03 \mathrm{BL} \mathrm{s}^{-1}\right)$ for heavily parasitised individuals (Table 1). Swimming performance

Table 1. Levels of parasite Lepeophtheirus salmonis load (lice density, corrected for body size of host Atlanic salmon Salmo salar), total abundance on the fish, and critical swimming speed ( $U_{\text {crit, }}$ mean \pm SE) for each infestation intensity and sea lice stage (COP: copepodid, CH: chalimus, PA: pre-adult, A: adult). Infestation intensities are 0 (no lice), 30 (mid-range) and 90 (high-range) copepodids per fish. BL: body length

\begin{tabular}{|c|c|c|c|c|c|c|c|c|}
\hline \multirow{2}{*}{ Lice stage } & \multirow[b]{2}{*}{$\mathrm{n}$} & \multicolumn{3}{|c|}{ Lice density (lice $\mathrm{cm}^{-2}$ ) } & \multicolumn{2}{|c|}{ Total abundance (lice fish ${ }^{-1}$ ) } & \multirow{2}{*}{$\begin{array}{c}U_{\text {crit }} \\
\left(\mathrm{cm} \mathrm{s}^{-1}\right)\end{array}$} & \multirow{2}{*}{$\begin{array}{c}U_{\text {crit }} \\
\left(\mathrm{BL} \mathrm{s}^{-1}\right)\end{array}$} \\
\hline & & Min. & Max. & Avg. & Min. & Max. & & \\
\hline \multicolumn{9}{|l|}{ No lice } \\
\hline COP & 19 & 0 & 0 & 0 & 0 & 0 & $74.88 \pm 1.36$ & $3.92 \pm 0.08$ \\
\hline $\mathrm{CH}$ & 30 & 0 & 0 & 0 & 0 & 0 & $80.95 \pm 0.70$ & $4.22 \pm 0.05$ \\
\hline PA & 30 & 0 & 0 & 0 & 0 & 0 & $81.59 \pm 1.08$ & $3.97 \pm 0.06$ \\
\hline A & 32 & 0 & 0 & 0 & 0 & 0 & $82.75 \pm 0.66$ & $4.20 \pm 0.04$ \\
\hline \multicolumn{9}{|c|}{ Mid-range infestation } \\
\hline $\mathrm{COP}$ & 17 & 0.01 & 0.12 & 0.04 & 2 & 27 & $79.22 \pm 1.10$ & $4.13 \pm 0.07$ \\
\hline $\mathrm{CH}$ & 30 & 0.01 & 0.16 & 0.03 & 1 & 26 & $79.40 \pm 1.06$ & $4.08 \pm 0.06$ \\
\hline PA & 29 & 0.01 & 0.10 & 0.02 & 1 & 25 & $80.36 \pm 0.77$ & $4.12 \pm 0.05$ \\
\hline A & 26 & 0.00 & 0.02 & $<0.01$ & 0 & 4 & $84.19 \pm 0.98$ & $4.28 \pm 0.05$ \\
\hline \multicolumn{9}{|c|}{ High-range infestation } \\
\hline COP & 19 & 0.05 & 0.39 & 0.13 & 9 & 69 & $76.99 \pm 1.35$ & $3.90 \pm 0.06$ \\
\hline $\mathrm{CH}$ & 30 & 0.06 & 0.60 & 0.19 & 14 & 102 & $78.28 \pm 0.91$ & $4.09 \pm 0.07$ \\
\hline PA & 30 & 0.04 & 0.29 & 0.11 & 7 & 52 & $78.82 \pm 0.60$ & $4.03 \pm 0.04$ \\
\hline A & 24 & 0.01 & 0.05 & 0.02 & 1 & 10 & $79.76 \pm 0.95$ & $4.13 \pm 0.06$ \\
\hline
\end{tabular}


was negatively correlated to lice density and fish length; however, sea lice life-history stage had little influence on the mean $U_{\text {crit }}$ across densities (Fig. 1, Table 2). When the 3 factors were incorporated into the multiple regression model, lice stages, lice density and fish length significantly contributed to $U_{\text {crit }}\left(\mathrm{R}^{2}=\right.$ $0.31, F_{5,310}=28.3, \mathrm{p}<0.001$; Table 2). Lice density had a large effect on $U_{\text {crit }}(\beta=-12.47)$ in the model, yet comparisons of single factor regressions showed that length had the strongest influence on performance compared to lice stage and lice density $\left(R^{2}=0.18\right.$ compared to 0.11 and 0.07 , respectively; Table 2). However, standardized $\beta$ values revealed a lesser importance of length to the chalimus and preadult lice stage model factors (Table 2). When tested in individual regression models, all factors contributed significantly to swimming performance (Table 2), and the full model including all parameters was a signifi-
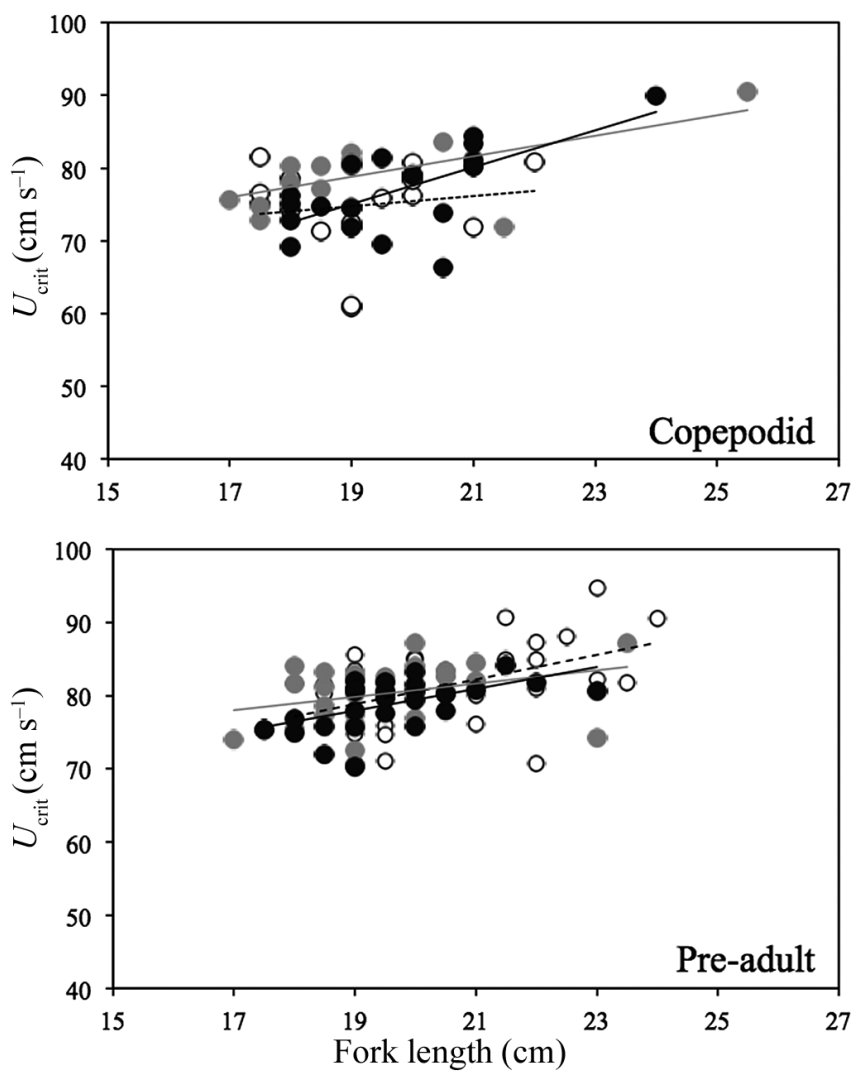

Table 2. Model parameter outputs for the effect of sea lice (Lepeophtheirus salmonis) stage, sea lice density and fork length of host Atlantic salmon Salmo salar on critical swimming speed $\left(U_{\text {crit, }} \mathrm{cm} \mathrm{s}^{-1}\right)$. Results are shown for the full model (lice stage + density + length) and for single parameter models. COP: copepodid, CH: chalimus, PA: pre-adult, A: adult lice stages. Stand.: standardised,

CI: confidence interval. Significant differences at $\mathrm{p}<0.05$

\begin{tabular}{|lcccccccc|}
\hline \multirow{2}{*}{ Factor } & \multirow{3}{*}{ Single model } & \multicolumn{6}{c|}{ Full model } \\
\cline { 5 - 8 } & $\mathrm{R}^{2}$ & $\mathrm{p}$ & & $\beta$ & Stand. $\beta$ & $\mathrm{p}$ & $\mathrm{CI} 2.5 \%$ & CI $97.5 \%$ \\
\hline Lice stage & 0.11 & $<0.001$ & - & - & - & - & - \\
CH vs. COP & - & - & 2.96 & 0.65 & $<0.001$ & 1.48 & 4.45 \\
PA vs. COP & & - & 2.39 & 0.68 & 0.002 & 0.90 & 3.89 \\
A vs. COP & - & - & 4.45 & 0.07 & $<0.001$ & 2.92 & 6.00 \\
Lice density & 0.07 & $<0.001$ & -12.47 & -0.19 & $<0.001$ & -18.96 & -5.99 \\
Length & 0.18 & $<0.001$ & 1.44 & 0.32 & $<0.001$ & 1.11 & 1.78 \\
\end{tabular}

cant improvement on the individual models $\left(F_{2,310}=\right.$ $45.89, \mathrm{p}<0.001)$. Plots of predicted values against standardised residuals (not shown) revealed even dispersion of data points around zero, satisfying assumptions of linearity, randomness and homoscedasticity. Q-Q plots indicate that observed residuals are within normal deviations from normality.
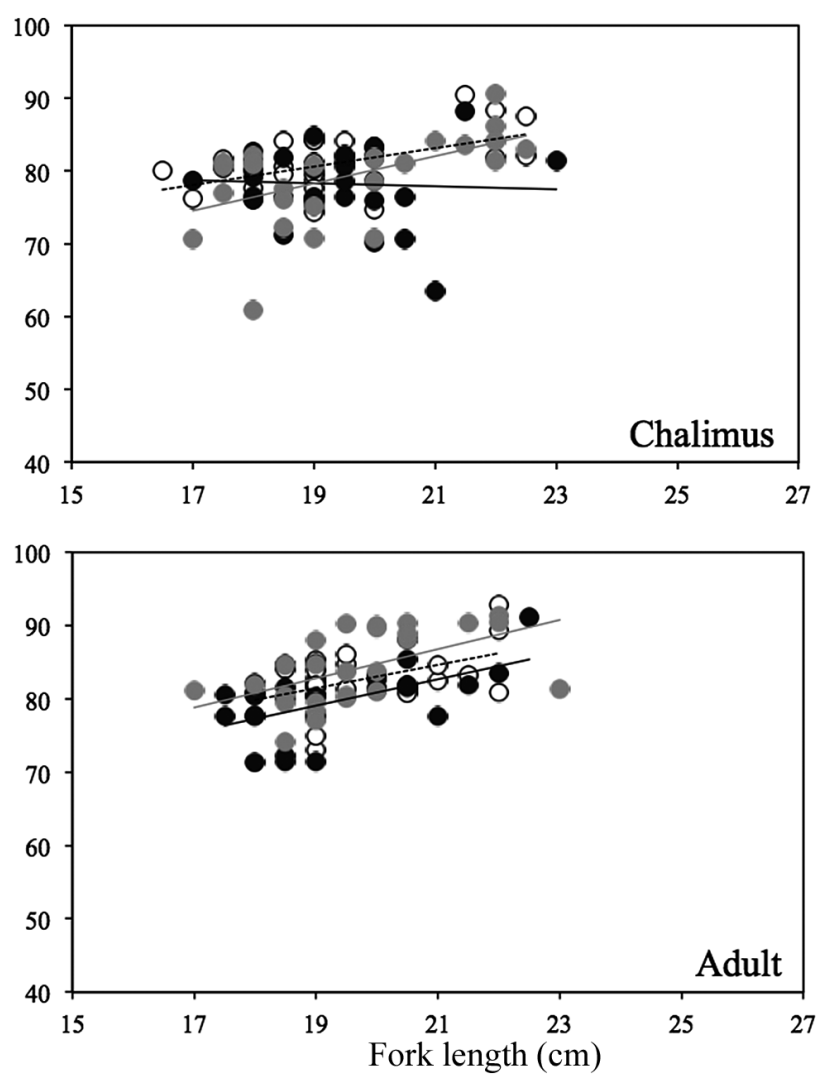

Fig. 1. Relationship between fish length and critical swimming speed ( $\left.U_{\text {crit }}\right)$ of host Atlantic salmon Salmo salar as tested in the swim flume, at the 4 sea lice (Lepeophtheirus salmonis) life-history stages examined. Increasing infestation densities are categorically represented with no lice (grey circles, grey line), mid-range (30 copepodids fish ${ }^{-1}$; open circles, dotted line), and high-range infestation density (90 copepodids fish $^{-1}$; black circles, black line) 


\section{DISCUSSION}

\section{Sea lice stages and swimming performance}

Sea lice life-history stage, infestation intensity, and fish length had a varying yet cumulative effect on swimming performance. Our study is one of few that have tested the impact of juvenile lice stages on the swimming performance of Atlantic salmon. Nendick et al. (2011) investigated the performance of wild juvenile pink salmon Oncorhynchus gorbuscha infested with chalimus and pre-adult 1 stages and found that they had a large negative effect on performance (when fish were $0.34 \mathrm{~g}$ in average body mass), irrelevant of parasite density. However, the interaction between pink salmon and Lepeophtheirus salmonis differs from that observed with Atlantic salmon, where migrating juveniles exposed to infective copedids are much smaller and exhibit a more dramatic physiological and immunological response to infestation (Wagner et al. 2008, Brauner et al. 2012). The physiological impacts of copepodid and chalimus stages are not as pronounced as those of the mobile stages, yet spikes in immune and histopathological responses have been described in Atlantic salmon infested by lice at these attached stages (Jónsdóttir et al. 1992, Tadiso et al. 2011). We found that critical swimming performance was relatively similar between infested and uninfested salmon at the copepodid life stage; however, at the chalimus stage, high parasite loads resulted in a larger decline in $U_{\text {crit }}$ with length. There is little difference between the copepodid and chalimus stages in terms of host physiological response (Bowers et al. 2000, Wagner et al. 2008), and our results suggest that infestation with copepodids imparts only a marginal cost on performance.

Pre-adult and adult L. salmonis are the sea lice stages expected to have the greatest physiological impact on their host (Jónsdóttir et al. 1992, Grimnes \& Jakobsen 1996, Bowers et al. 2000) and their hosts' swimming performance (Wagner et al. 2003, Mages \& Dill 2010). When sea lice moult into the mobile preadult stage, feeding behaviour changes and their consumption increases, which can result in host blood loss and osmoregulatory failure (Brandal et al. 1976, Grimnes \& Jakobsen 1996, Sackville et al. 2011). Wagner \& McKinley (2004) predicted that the feeding rates of $L$. salmonis could induce anaemia, reducing the critical swimming performance of Atlantic salmon. In our study, there was no scaling effect of sea lice life-history stage on critical swimming performance. Standardized $\beta$ values indicate that chalimus and pre-adult stages have a more positive impact on $U_{\text {crit }}$ compared to adult stages (Table 2) when parasite density and length are held constant. However, mean $U_{\text {crit }}$ among the stages varied by $4.97 \mathrm{~cm} \mathrm{~s}^{-1}\left(0.20 \mathrm{BL} \mathrm{s}^{-1}\right)$ for mid-range densities and by $1.83 \mathrm{~cm} \mathrm{~s}^{-1}\left(0.23 \mathrm{BL} \mathrm{s}^{-1}\right)$ for high-range densities, indicating a small effect size due to lice stage. Although our results arose with higher infestation densities at the chalimus and pre-adult stages compared to adults, it is possible that the cost of infestation with high abundance of younger life-history stages is less than that of adult lice when present in low abundances.

\section{Parasite density and swimming performance}

Increasing sea lice density had a negative impact on $U_{\text {crit, }}$ which was more pronounced when density was $>0.7$ lice $\mathrm{cm}^{-2}$ (i.e. high-range infestation density). Wagner et al. (2003) demonstrated a similar decline in $U_{\text {crit, }}$ from $2.6 \mathrm{BL} \mathrm{s}^{-1}$ in unparasitised Atlantic salmon, to 2.4 and $2.1 \mathrm{BL} \mathrm{s}^{-1}$ in low and highly infested fish, respectively. In their trial, infestation

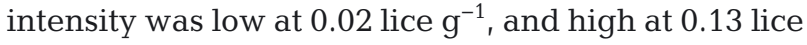
$\mathrm{g}^{-1}$, whereas our fish had a mean of 0.06 and 0.29 lice $\mathrm{g}^{-1}$ for our mid- and high-range infestation pressure groups (across all lice stages), respectively. However, we observed higher $U_{\text {crit }}$ for infested fish, with means of 4.15 and $4.04 \mathrm{BL} \mathrm{s}^{-1}$ for mid- and high-range infestation levels. This relationship has also been observed in wild juvenile pink salmon $O$. gorbuscha, with high infestation intensities (1-5 adult females per fish; Mages \& Dill 2010). Infestations of up to 0.04 adult sea lice $\mathrm{g}^{-1}$ are enough to induce physiological changes in the epithelial layer and at the molecular level (Nolan et al. 1999), which supports the evidence for reduced critical swimming speed at low infestation intensities. Future studies should compare the impact of sea lice infestation on performance of wild and farmed salmonids, to determine if selection pressures for infestation tolerance differ between the 2 as a result of their divergent ecological profiles (e.g. Gross 1998).

\section{Implications for aquaculture management}

Multiple environmental issues have led to increasing interest in culturing salmon at more exposed offshore sites (Holmer 2010). Locations considered suitable for farm sites are generally associated with high current velocities that improve production para- 
meters such as fish welfare, the rapid dispersion of waste, oxygen and temperature conditions, and the avoidance of nutrient run-off from rivers (Benetti et al. 2010, Huntingford \& Kadri 2013). Given lice infestation rates decline at high swimming velocities (1.4 BL sec ${ }^{-1}$; Samsing et al. 2014), shifts towards faster current sites will become more prevalent. The implementation of off-shore salmon aquaculture requires a deep understanding of the welfare implications of being held at high water current velocities (Tudorache et al. 2013). To avoid negative physiological and welfare impacts, current velocities must not approach the limit for sustained swimming in Atlantic salmon (Jørgensen \& Jobling 1993, Solstorm et al. 2015, 2016), a limit that shifts depending on biotic factors such as body size and parasite load. Although swimming speeds between 0.2 and 3.0 BL $\mathrm{s}^{-1}$ have been observed for salmon held in sea cages (Dempster et al. 2008, Korsøen et al. 2009), critical swimming speed has been experimentally determined at $1.9-8.3 \mathrm{BL} \mathrm{s}^{-1}$ for a range of size cohorts without infestation (Peake 2008). Here we have shown that critical swimming performance is reduced with increasing parasite load, and advise that considerations of acceptable current velocities for new farm sites take into account potential infestation pressure in combination with sustained swimming limits for the size group of salmon. Although present governmental legislation is strict for infestation prevalence and intensity in farms, particularly in Norway (Torrissen et al. 2013), observed sea lice loads are not always negligible (www.lusedata.no), and this may affect the ability of fish to hold their position in the water current if $>0.02$ lice $\mathrm{cm}^{-2}$ (Wagner et al. 2003, present study).

\section{Implications for wild salmonids}

The impact of increased infestation pressure arising from salmon farming on the health of wild salmonid populations remains a contentious issue (Krkošek et al. 2007, 2014, Jackson et al. 2013). Evidence for lethal thresholds are supported by results from monitoring programs of wild populations: surveys have rarely found post-smolts with sea lice loads $>0.1$ lice $\mathrm{g}^{-1}$, while the threshold has recently been classified as $100 \%$ mortality for sea trout with $>0.3$ lice $\mathrm{g}^{-1}$ (Taranger et al. 2015). Even with low infestation intensity, our study shows that parasite loads of at least 0.01 lice $\mathrm{g}^{-1}\left(0.006\right.$ lice $\left.\mathrm{cm}^{-2}\right)$, at any life-history stage, can reduce the critical swimming performance of post-smolts. This may contribute to their declining survival with sea lice infestation, as the migration speed of post-smolts is vital for their survival through coastal areas where predation risk is high (Thorstad et al. 2012). Additionally, impaired swimming performance will reduce efficient predator avoidance and feeding behaviours in strong currents.

Increasing infestation level is likely to reduce the host's ability to sustain swimming performance in the pelagic phase, due to diminished aerobic capacity, osmoregulatory function and risk of secondary infestation (Tully \& Nolan 2002, Wagner et al. 2003, Taranger et al. 2015), particularly after sea lice transition into the mobile pre-adult and adult stages. Hatchery-reared Atlantic salmon that were treated for sea lice before release had a higher rate of recapture compared to untreated salmon, suggesting that protection against infestation during out-migration facilitates survival (Krkošek et al. 2013, Skilbrei et al. 2013). Smolts treated against lice may grow more rapidly than untreated controls during their first year at sea (Skilbrei \& Wennevik 2006), and untreated smolts stay longer at sea before they mature and return to the rivers (Vollset et al. 2014). Current evidence suggests that infestation with sea lice is the underlying cause of these observations, whereby our results on swimming performance could add to the multiple mechanisms of fitness decline with infestation.

Acknowledgements. We thank T. Vågseth and staff from the Institute of Marine Research at the Matre research station for their technical assistance and O. Skilbrei for comments on the manuscript. This research was funded by an Australian Research Council Future Fellowship grant (awarded to T. Dempster), and carried out partially within the Norwegian Research Council Centre for Research-Based Innovation on Exposed Aquaculture Operations (237790). This experiment was conducted according to the regulations stipulated by the Norwegian Regulation on Animal Experimentation (application ID: 7131).

\section{LITERATURE CITED}

Barber I, Hoare D, Krause J (2000) Effects of parasites on fish behaviour: a review and evolutionary perspective. Rev Fish Biol Fish 10:131-165

> Benetti DD, Benetti GI, Rivera JA, Sardenberg B, O'Hanlon B (2010) Site selection criteria for open ocean aquaculture. Mar Technol Soc J 44:22-35

Bjørn PA, Finstad B (1998) The development of salmon lice (Lepeophtheirus salmonis) on artificially infected post smolts of sea trout (Salmo trutta). Can J Zool 76:970-977

$>$ Bowers JM, Mustafa A, Speare DJ, Conboy GA, Brimacombe M, Sims DE, Burka JF (2000) The physiological response of Atlantic salmon, Salmo salar L., to a single experimental challenge with sea lice, Lepeophtheirus salmonis. J Fish Dis 23:165-172 
Brandal PO, Egidius E, Romslo I (1976) Host blood: a major food component for the parasitic copepod Lepeophtheirus salmonis, Krøyeri, 1838 (Crustacea: Caligidae). Norw J Zool 24:341-343

Brauner CJ, Sackville M, Gallagher Z, Tang S, Nendick L, Farrell AP (2012) Physiological consequences of the salmon louse (Lepeophtheirus salmonis) on juvenile pink salmon (Oncorhynchus gorbuscha): implications for wild salmon ecology and management, and for salmon aquaculture. Philos Trans R Soc Lond B 367:1770-1779

Brett JR (1964) The respiratory metabolism and swimming performance of young sockeye salmon. J Fish Res Board Can 21:1183-1226

Costello MJ (2006) Ecology of sea lice parasitic on farmed and wild fish. Trends Parasitol 22:475-483

Costello MJ (2009) How sea lice from salmon farms may cause wild salmonid declines in Europe and North America and be a threat to fishes elsewhere. Philos Trans $\mathrm{R}$ Lond Soc B 276:3385-3394

> Dempster T, Juell JE, Fosseidengen JE, Fredheim A (2008) Behaviour and growth of Atlantic salmon (Salmo salar L.) subjected to short-term submergence in commercial scale sea-cages. Aquaculture 276:103-111

Field A, Miles J, Field Z (2012) Discovering statistics using R. Sage Publications, London

> Grimnes A, Jakobsen PJ (1996) The physiological effects of salmon lice (Lepeophtheirus salmonis) infection on post smolts of Atlantic salmon (Salmo salar). J Fish Biol 48: 1179-1194

Gross MR (1998) One species with two biologies: Atlantic salmon (Salmo salar) in the wild and in aquaculture. Can J Fish Aquat Sci 55(Suppl 1):131-144

> Hammer C (1995) Fatigue and exercise tests with fish. Comp Biochem Physiol A Mol Integr Physiol 112:1-20

> Hayashida K, Nii H, Tsuji T, Miyoshi K, Hamamoto S, Ueda $H$ (2013) Effects of anesthesia and surgery on $U_{\text {crit }}$ performance and $\mathrm{MO}_{2}$ in chum salmon, Oncorhynchus keta. Fish Physiol Biochem 39:907-915

Holmer M (2010) Environmental issues of fish farming in offshore waters: perspectives, concerns and research needs. Aquacult Environ Interact 1:57-70

Huntingford F, Kadri S (2013) Exercise, stress and welfare. In: Palstra AP, Planas JB (eds) Swimming physiology of fish: towards using exercise to farm a fit fish in sustainable aquaculture. Springer, London, p 161-174

> Jackson D, Cotter D, Newell J, McEvoy S and others (2013) Impact of Lepeophtheirus salmonis infestations on migrating Atlantic salmon, Salmo salar L., smolts at eight locations in Ireland with an analysis of lice-induced marine mortality. J Fish Dis 36:273-281

> Johansson D, Laursen F, Fernö A, Fosseidengen JE and others (2014) The interaction between water currents and salmon swimming behaviour in sea cages. PLoS ONE 9:e97635

Johnson SC, Albright LJ (1991) Development, growth, and survival of Lepeophtheirus salmonis (Copepoda: Caligidae) under laboratory conditions. J Mar Biol Assoc UK 71:425-436

Jónsdóttir H, Bron JE, Wootten R, Turnbull JF (1992) The histopathology associated with the pre-adult and adult stages of Lepeophtheirus salmonis on the Atlantic salmon, Salmo salar L. J Fish Dis 15:521-527

Jørgensen EH, Jobling M (1993) The effects of exercise on growth, food utilization and osmoregulatory capacity of juvenile Atlantic salmon, Salmo salar. Aquaculture 116: 233-246
Kolok AS (1999) Interindividual variation in the prolonged locomotor performance of ectothermic vertebrates: a comparison of fish and herpetofaunal methodologies and a brief review of the recent fish literature. Can J Fish Aquat Sci 56:700-710

Korsøen $\varnothing$, Dempster T, Fjelldal PG, Oppedal F, Kristiansen TS (2009) Long-term culture of Atlantic salmon (Salmo salar L.) in submerged cages during winter affects behaviour, growth and condition. Aquaculture 296:373-381

Krkošek M, Ford JS, Morton A, Lele S, Myers RA, Lewis MA (2007) Declining wild salmon populations in relation to parasites from farm salmon. Science 318:1772-1775

Krkošek M, Revie CW, Gargan PG, Skilbrei OT, Finstad B, Todd CD (2013) Impact of parasites on salmon recruitment in the Northeast Atlantic Ocean. Proc R Soc Lond B Biol Sci 280:20122359

Krkošek M, Revie CW, Finstad B, Todd CD (2014) Comment on Jackson et al. 'Impact of Lepeophtheirus salmonis infestations on migrating Atlantic salmon, Salmo salar L., smolts at eight locations in Ireland with an analysis of lice-induced marine mortality'. J Fish Dis 37:415-417

> Mages PA, Dill LM (2010) The effect of sea lice (Lepeophtheirus salmonis) on juvenile pink salmon (Oncorhynchus gorbuscha) swimming endurance. Can J Fish Aquat Sci 67:2045-2051

Murray AG, Wardeh M, McIntyre KM (2016) Using the $\mathrm{H}$-index to assess disease priorities for salmon aquaculture. Prev Vet Med 126:199-207

Nendick L, Sackville M, Tang S, Brauner CJ, Farrell AP (2011) Sea lice infection of juvenile pink salmon (Oncorhynchus gorbuscha): effects on swimming performance and post-exercise ion balance. Can J Fish Aquat Sci 68: 241-249

Nolan DT, Reilly P, Wendelaar Bonga SE (1999) Infection with low numbers of the sea louse Lepeophtheirus salmonis induces stress-related effects in postsmolt Atlantic salmon (Salmo salar). Can J Fish Aquat Sci 56: 947-959

O'Shea B, Mordue-Luntz AJ, Fryer RJ, Pert CC, Bricknell IR (2006) Determination of the surface area of a fish. J Fish Dis 29:437-440

Peake SJ (2008) Swimming performance and behaviour of fish species endemic to Newfoundland and Labrador: a literature review for the purpose of establishing design and water velocity criteria for fishways and culverts. Canadian Manuscript Report of Fisheries and Aquatic Sciences No. 2843, Oceans and Habitat Mangement Branch, Fisheries and Oceans Canada, Ottawa

Plaut I (2001) Critical swimming speed: its ecological relevance. Comp Biochem Physiol Part A Mol Integr Physiol 131:41-50

R Core Team (2015) R: a language and environment for statistical computing. R Foundation for Statistical Computing, Vienna. www.R-project.org/

> Sackville M, Tang S, Nendick L, Farrell AP, Brauner CJ (2011) Pink salmon (Oncorhynchus gorbuscha) osmoregulatory development plays a key role in sea louse (Lepeophtheirus salmonis) tolerance. Can J Fish Aquat Sci 68:1087-1096

- Samsing F, Oppedal F, Johansson D, Bui S, Dempster T (2014) High host densities dilute sea lice Lepeophtheirus salmonis loads on individual Atlantic salmon, but do not reduce lice infection success. Aquacult Environ Interact 6:81-89

Schmit O, Mezquita F (2010) Experimental test on the use of 
MS-222 for Ostracod anaesthesia: concentration, immersion period and recovery time. J Limnol 69:350-352

Skilbrei OT, Wennevik V (2006) Survival and growth of searanched Atlantic salmon, Salmo salar L., treated against sea lice prior to release. ICES J Mar Sci 63:1317-1325

Skilbrei OT, Finstad B, Urdal K, Bakke G, Kroglund F, Strand R (2013) Impact of early salmon louse, Lepeophtheirus salmonis, infestation and differences in survival and marine growth of sea-ranched Atlantic salmon, Salmo salar L., smolts 1997-2009. J Fish Dis 36:249-260

Solstorm F, Solstorm D, Oppedal F, Fernö A, Fraser TWK, Olsen RE (2015) Fast water currents reduce production performance of post-smolt Atlantic salmon Salmo salar. Aquacult Environ Interact 7:125-134

Solstorm F, Solstorm D, Oppedal F, Olsen RE, Stien LH, Fernö A (2016) Not too slow and not too fast: water currents affect group structure, aggression and welfare in post-smolt Atlantic salmon Salmo salar. Aquacult Environ Interact 8:339-347

Tadiso TM, Krasnov A, Skugor S, Afanasyev S, Hordvik I, Nilsen F (2011) Gene expression analyses of immune responses in Atlantic salmon during early stages of infection by salmon louse (Lepeophtheirus salmonis) revealed bi-phasic responses coinciding with the copepod-chalimus transition. BMC Genomics 12:141

Taranger GL, Karlsen Ø, Bannister RJ, Glover KA and others (2015) Risk assessment of the environmental impact of Norwegian Atlantic salmon farming. ICES J Mar Sci 72: 997-1021

Thorstad EB, Whoriskey F, Uglem I, Moore A, Rikardsen AH, Finstad B (2012) A critical life stage of the Atlantic salmon Salmo salar: behaviour and survival during the smolt and initial post-smolt migration. J Fish Biol 81: $500-542$

Editorial responsibility: Bengt Finstad, Trondheim, Norway
Thorstad EB, Todd CD, Uglem I, Bjørn PA and others (2015) Effects of salmon lice Lepeophtheirus salmonis on wild sea trout Salmo trutta-a literature review. Aquacult Environ Interact 7:91-113

- Torrissen O, Jones S, Asche F, Guttormsen A and others (2013) Salmon lice-impact on wild salmonids and salmon aquaculture. J Fish Dis 36:171-194

- Tucker CS, Sommerville C, Wootten R (2002) Does size really matter? Effects of fish surface area on the settlement and initial survival of Lepeophtheirus salmonis, an ectoparasite of Atlantic salmon Salmo salar. Dis Aquat Org 49:145-152

Tudorache C, de Boeck G, Claireaux G (2013) Forced and preferred swimming speeds of fish: a methodological approach. In: Palstra AP, Planas JB (eds) Swimming physiology of fish: towards using exercise to farm a fit fish in sustainable aquaculture. Springer, London, p 81-108

Tully O, Nolan DT (2002) A review of the population biology and host-parasite interactions of the sea louse Lepeophtheirus salmonis (Copepoda: Caligidae). Parasitology 124:S165-S182

Videler JJ (1993) Fish swimming. Chapman \& Hall, London $>$ Vollset KW, Barlaup BT, Skoglund H, Normann ES, Skilbrei OT (2014) Salmon lice increase age-at-maturity of Atlantic salmon (Salmo salar). Biol Lett 10:20130896

Wagner GN, McKinley RS (2004) Anaemia and salmonid swimming performance: the potential effects of sublethal sea lice infection. J Fish Biol 64:1027-1038

Wagner GN, McKinley RS, Bjørn PA, Finstad B (2003) Physiological impact of sea lice on swimming performance of Atlantic salmon. J Fish Biol 62:1000-1009

Wagner GN, Fast MD, Johnson SC (2008) Physiology and immunology of Lepeophtheirus salmonis infections of salmonids. Trends Parasitol 24:176-183

Submitted: December 2, 2015; Accepted: May 4, 2016 Proofs received from author(s): June 6, 2016 